\section{A Disability Identification- Diagnosis Process in Children with Disabilities Under Six Years of Age and Associated Factors}

\section{Nguyen Thi Minh Thuy ${ }^{1 *}$, Tran Quy Cat ${ }^{1}$, Nguyen Huu Chut ${ }^{2}$, Do Chi Hung ${ }^{3}$ and Nguyen Van Le ${ }^{4}$}

${ }^{1}$ The Center of Research and Action for Comprehensive Health, Hanoi, Vietnam

${ }^{2}$ Department of Rehabilitation, National Hospital of Pediatrics, Hanoi, Vietnam

${ }^{3}$ Faculty of Clinical Medicine, Hanoi University of Public Health, Hanoi, Vietnam

${ }^{4} \mathrm{Ha}$ Dong Medical College, Hanoi, Vietnam

\begin{abstract}
Background: Disability is a cause of burden for families and society. Early detection of disability assists disabled children with early intervention, enhances their function ability and improves their quality of life and social inclusion.
\end{abstract}

Objective: Describe the process of disability identification and diagnosis for children with disabilities under six years old and related factors of this process.

Method: This is a cross-sectional study with interviews with 165 mothers of children with disabilities under six years old in four districts of Hanoi in 2015. The study focused on a process of disability identification and diagnosis among children with disabilities.

Result: Of those who identified the first sign of disability or abnormality in a child, $84.24 \%$ were parents. On the average, children were identified with disability when they were 12.28 months old and

*Corresponding author: Nguyen Thi Minh Thuy, The Center of Research and Action for Comprehensive Health, Hanoi, Vietnam, Tel: +84 376169999; Email: thuyntmhd@gmail.com

Citation: Thuy NTM, Cat TQ, Chut NH, Hung DC, Le NV (2020) A Process for Early Detection and Early Identification of Disability in Children Under Six Years of Age and other Related Factors. J Phys Med Rehabil Disabil 6: 044.

Received: March 04, 2020; Accepted: March 17, 2020; Published: March 24, 2020

Copyright: ( 2020 Thuy NTM, et al. This is an open-access article distributed under the terms of the Creative Commons Attribution License, which permits unrestricted use, distribution, and reproduction in any medium, provided the original author and source are credited. suspicion of disability was confirmed when they were 14.64 months old. They were brought to a health clinic for a disability check and were detected with disability by professionals when they were on average 23.39 months old. Results of hierarchical regression analysis revealed that mothers accessing to information about early identification and detection of disability, children with congenital disability, or/and mobility disability, are identified with disability earlier while older children have more possibility to be identified later. Discussions with health staff about the signs of sensory and mobility disability and intellectual disability resulted in children being diagnosed and identified with disability earlier, while later diagnosis of disability resulted if children were identified at a later time.

Conclusion: Provision of information to parents regarding disability detection and identification, especially information about sensory disability, mental disability and intellectual disability, and encouraging parents to discuss with health staff when disability or abnormality is identified, are effective measures to ensure early identification and detection of disability for children.

Keywords: Children with disability and signs of disability/abnormality; Early identification and detection of disability; Time

\section{Introduction}

According to WHO, in the world population, between 785 million $(15.6 \%)$ to 975 million $(19.4 \%)$ people over 15 years old and 93 million $(5,1 \%)$ children under 14 years old, have disability [1]. According to GSO statistics on a disability survey of Vietnam, the rate of disability in Vietnam is $7.06 \%$ of which $2.74 \%$ are children 2-4 years old with disability, and $2.8 \%$ are children from 5-17 years old [2]. "Children with disability" is a health issue that needs attention internationally and nationally.

Care of People With Disability (PWD) in general or Children With Disability (CWD) in particular is a burden in terms of time [3], financial resources $[4,5]$, work $[5,6]$ and health of all family members, especially the direct career [6]. In addition, disability is a cost burden for the nation (ngân sách quốc gia), and for health care and social welfare [1].

However, according to WHO, $70 \%$ of disability can be avoided for children if appropriate disability prevention programs are carried out for pregnant women [7]. The early years of children are important because they are developing fast. Therefore, children should be provided with the best possible conditions for their development, with the earliest detection of disability [8]. Developmental screening for children is an effective measure for disability detection and identification for children [9]. Disability identification is a first basic step for early disability intervention and rehabilitation for children with disability, helping children with disability in social inclusion, reducing the burden for family and society. According to Shonkoff et al., [10], intervention before kindergarten age is beneficial for children regarding schooling and social and economic development, and can save US $\$ 30,000$ to US $\$ 100,000$ for each child with disability [10]. 
A study conducted by Markides [11] indicated that those children who were identified with loss of hearing ability at 0 to six months, and for whom intervention was immediately provided after identification, would develop their vocabulary and sign-language better than those children who were detected and identified as having disability later [11].

\section{Age of disability identification}

Some studies on autism indicate that parents usually identified their children's first symptom of autism when children were 2.5 to 3 years old, and autism is usually diagnosed when the children were 3 years old $[12,13]$. A study on "Early detection and early intervention for children with autism in Vietnam" carried out by Bahr Weiss revealed that the average age for detection of the signs of autism is 2.56 years [12]. Another study conducted by David S. Mandell in Pennsylvania from June to September 2004 indicated that the average age of children when diagnosed with an autistic disorder was 3.1 years, for PDD-NOS (atypical disorder) 3.9 years, and for Asperger's 7.1 years [13].

Some studies on developmental disorders indicated that close family members identified their children having signs of abnormality when they were 8 to 9 months, and the disability was diagnosed and detected when the children were one year old $[14,15]$. A study carried out by Yoshiaki revealed that a timeframe for parents identifying disability for their children was from 9-10 months to 3.5 years old. This was also time for parents receiving information about suspicion of disability from different agencies such as kindergarten teachers $(0.3 \%$ in Japan, $9.2 \%$ in China, and 6.4\% in Vietnam), health clinics $(67.6 \%$ in Japan, $1.7 \%$ in China, and $7.4 \%$ in Vietnam) and hospitals (12\% in Japan, $76.7 \%$ in China and $57.4 \%$ in Vietnam). Parents were informed with accurate results from doctors when their children were from 1.5 to 4 years old [14]. Another study carried out by Kathleen Hebbeler et al., [15] during more than 10 years from 1996, with participation from 3,338 under three-year-old children and their families from 93 districts in 23 states in the United States, indicated that the average age for identification of disability or developmental disorders was from 8.8 months and the children received intervention when they were 14 months old [15].

Other studies carried out for children with hearing difficulty indicated that first suspicion factors were detected when children were one year old and the children were diagnosed when 1.5 years old and received intervention when nearly two years old [16-18]. Zahra Jafari carried out a study with 86 children under 6 years old with hearing difficulty in Tehran, Iran. Jafari reported that the average age of suspicion, diagnosis and intervention was $12,6 \pm 8,9 ; 15,2 \pm 9,3$ and $22,3 \pm$ 11,6 months respectively [16]. A study conducted in Illinois showed that the average age for suspicion and diagnosis of hearing loss was 8.16 months, with the use of hearing assistive devices taking place at 19.05 months [17]. A study conducted in Haiphong province in Vietnam indicated that the average age for identification, diagnosis, and use of hearing assistive devices was 21.3, 30.4 and 30 months respectively [18].

\section{Roles of families and related stakeholders in disability identification and diagnosis}

Historically, the role of parents in caring for children with disability has been recognized. Parents also play the main role in disability identification for their children. Studies indicate that parents are the first people to identify signs of abnormality in their children and it is parents who decide to take their children for checkups and who receive results of disability diagnosis and disability detection or determination. A study on "the need of children with autism and families: a comparative analysis of Japan, Trung Quoc and Vietnam" by Yoshiaki Takeuchi et al., [14] reported that the mother is the first person to have a suspicion of their child's disability (61\% in Japan and Vietnam and $72 \%$ in China), followed by the father $(6.5 \%$ in Japan and China, and $9 \%$ in Vietnam). Another study on "age for disability diagnosis, use of hearing assistive devices and intervention for children (tre so sinh) and children with hearing impairment: interviews from mothers/fathers" by Prendergast SG et al., [17] indicated that $61.2 \%$ of parents, on having a suspicion of their child's disability, bring the child to a health clinic for a checkup and diagnosis. Another study conducted by [16] on "age for suspicion, diagnosis, amplification and intervention in deaf children" indicated that $55.9 \%$ of those who identified the hearing loss for children were their close family members (parents, sisters and brothers).

Besides parents, other people close to the family, other direct individuals such as kindergarten teachers and health staff, also play important roles in identifying disabilities in children. Kindergarten teachers spend more than 8 hours a day with children at a time when the children are involved in the most activities during the day. However, some types of disabilities can only detected when children start schooling, such as intellectual disability or learning disability, or autistic spectrum disorder [19,20]. Kindergarten teachers can detect disability or signs of abnormality via learning and play activities organized for children at the pre-school. A study conducted by Yoshiaki Takeuchi et al., indicated that nearly $8 \%$ of kindergarten teachers $(6.5 \%$ in Japan, $7.4 \%$ in China and $3.2 \%$ in Vietnam) informed of their suspicion of disability or slow development of children in their class [14]. In Vietnam, health staff working in the public health system plays important roles in disability services for people with disability, including disability detection [21]. Yoshiaki Takeuchi indicated that public health nurses played a role in detecting signs of disability or informed of the disability situation of children $(17.9 \%$ in Japan, $0.8 \%$ in China, 2.1\% in Vietnam) [14].

\section{Factors relating to early disability detection and identification}

Some factors relating to time of disability detection and identification included: family economy, disability status, and ages of children $[13,16,18,22]$. According to David S. Mandell [13], the factors included: the average age of children being detected with autistic spectrum disorder relates to economic conditions (children who live in poor families were detected with disability at 0.9 years later than those who lived in better off families); residency areas (children who live in rural areas were detected with disability at 0.4 years later than those living in the urban areas); and disability status (children with speech disability were detected 1.2 years earlier) [13]. A study conducted by Zahra Jafari in India indicated the differences in statistics between the household economic situation and the average age of disability identification, diagnosis and intervention of deaf children $(p<0,05)[16]$.

A study conducted by Joshua R. Mann et al., indicated the statistical relationship between age and origin of children and the age of children being detected with disability [22]. A study conducted in Hai Phong revealed that children with hearing impairment living in 
the city or centre areas were detected with disability, diagnosed, and provided with hearing assistive devices earlier than those living in the areas far from the centre $(\mathrm{p}<0,01)$. Children with severe hearing impairment tend to be detected and diagnosed earlier than those with less hearing impairment $(\mathrm{p}<0,01)[18]$.

\section{Aim/Objectives}

The aim of this study is to describe the age points in disability identification - diagnosis process and related factors in Children with Disabilities (CWDs) under 6 years old in Hanoi, the capital of Vietnam.

\section{Methods}

\section{Study setting}

This study is part of the findings identified in the primary assessment of an intervention study on development and assessment of the effectiveness of an early disability detection and identification model for children under 6 years old in Hanoi. The intervention was implemented over three years 2014-2016 and the funding source was provided by the Hanoi Department of Sciences and Technology. This study consisted of three key parts: (i) primary assessment of the situation of early disability detection and identification for children, and knowledge, attitudes and practices of parents, teachers and health staff in relation to early detection and identification; (ii) developing and implementing information communication/propaganda programs (training, dissemination of leaflets, posters, reminder at school meetings and assemblies, and immunization campaigns; and (iii) assessment of the effectiveness of intervention programs for early disability detection and identification for children, including factors on improved knowledge, attitude and practices of parents, teachers and health staff on early identification and detection of disability. This is a comprehensive study on the primary assessment of implementation of the intervention program for early disability detection and identification for children in four districts of Hanoi. To date, 18 articles have been written and published locally based on the results of this intervention program.

\section{Timeline and location}

The study was conducted in four districts, representing four ecological regions of Hanoi, including Hoai Duc, Quoc Oai, Cau Giay, and Dan Phuong districts from October 2014 to February 2015.

\section{Study design \\ Cross-sectional study sampling}

All children under 6 years of age who had been identified with disability in a community-based survey on disability were selected for this study. This study was carried out in 11 wards/communes in 1 Quan and three districts of Hanoi, with the total number of participants being 10,919 children under 6 years old. The average age of children participants with disability was 39.3 months, with the majority of them being more than 36 months old (58.8\%); $59.4 \%$ of the children were male and $40.6 \%$ were female. Eighty-four point four per cent (84.8\%) of the participants were the first or second child in the family and only $15.2 \%$ was the third child or more. A majority of children under one year old had hearing and speech impairment (53.3\%), followed by visual impairment (30.3\%), intellectual disability (29.7\%), and $9.7 \%$ had mental disability. The rate of those having two or more types of disability was relatively high (43\%); $24.8 \%$ of them having acquired disability and $75.2 \%$ having congenital disability (Table 1). Nearly one quarter of the children participants were born of mothers having health problems during pregnancy (bleeding, pain, and sickness) and one third of them had medical intervention at birth (surgery, use of forceps, Cesarean Section). Nearly $23 \%$ of the children were born after less than 37 weeks of gestation and $13.9 \%$ weighed less than 2500 grams on delivery, with $17 \%$ of them being asphyxiated at birth. Nearly $78.2 \%$ of the families that have children who participated in the study had from one to two children, and $14.5 \%$ of them had children with disability. Only $5 \%$ of the children lived in poor families and nearly half of children participating in the study lived in families with more than three generations in the household. More than half of mothers participating in the study had never received any information about early identification and detection of disability $(53.9 \%)$, while $87.9 \%$ of them were interested in monitoring the abnormality of their children.

\section{Data collection procedures}

Data collection was carried out in the following steps: (i) A household baseline survey was undertaken to make a list of children under 6 years old with suspected disability. This activity was done by village health staff by inviting families to a meeting at the community hall. This meeting was also to disseminate information about health care relating to children. Each family was provided with a screening questionnaire and they were required to answer each question. After the meeting, the village health staff collected all completed questionnaires. Those families that could not come to the meeting were visited by village health staff at their homes and they were asked to complete the questionnaire at home. Heads of the commune health clinics made a final list of children under 6 years old with suspected disability and sent it to study members for the disability screening activity. (ii) Disability screening for children with suspected disability was conducted. Invitations were sent to those who were on the list for disability screening. The invitations also indicated that the mothers needed to accompany their children for the screening as they were invited for an interview as well. Doctors from National Pediatrics Hospital did the disability screening. (iii) Interviews were conducted with the mothers of the children with disability. After children were detected by doctors as having a disability, the mothers of those children were invited to participate in the interviews about the disability identification - diagnosis process in their children. Disability screening and interviews were carried out at the commune health clinics. Interviews were done by public health university graduates who were trained in interviewing using the questionnaires. Each interview was for 30 minutes. Mothers were provided with fee tokens for travel support and gifts after the interviews. The data collectors collected all the filled questionnaires and checked to make sure all questions were answered and missing information and data re-collected.

\section{Use of data collection tools}

This was a quantitative study using two main tools: The questionnaire of disability identification and detection for family/households, and the structured questionnaire for interviewing mothers with children with disability. Questionnaires used for families were developed based on the questions for disability identification developed in the training manual "guide for local supervisors" of the World Health Organization [23]. 


\begin{tabular}{|c|c|c|}
\hline Characteristic & Frequency & $\%$ \\
\hline \multicolumn{3}{|l|}{ Demographic Information of children } \\
\hline \multicolumn{3}{|l|}{ Age } \\
\hline$\leq 36$ months & 68 & 41.21 \\
\hline$>36$ months & 97 & 58.79 \\
\hline \multicolumn{3}{|l|}{ Gender } \\
\hline Male & 98 & 59.39 \\
\hline Female & 67 & 40.61 \\
\hline \multicolumn{3}{|l|}{ Birth order } \\
\hline First Child & 84 & 50.91 \\
\hline Second Child & 56 & 33.94 \\
\hline Third and onward & 25 & 15.15 \\
\hline \multicolumn{3}{|l|}{ Forms of disability } \\
\hline Visual & 50 & 30.3 \\
\hline Speaking and hearing & 88 & 53.33 \\
\hline Physical & 46 & 27.88 \\
\hline Intellectual & 49 & 29.7 \\
\hline Intellectual - Mental & 16 & 9.7 \\
\hline Others & 24 & 14.55 \\
\hline \multicolumn{3}{|l|}{ Causes } \\
\hline Congenital disability & 124 & 75.15 \\
\hline Acquired disability & 41 & 24.85 \\
\hline \multicolumn{3}{|l|}{\begin{tabular}{|l|} 
Number of disabilities each child \\
\end{tabular}} \\
\hline 1 disability & 94 & 56.97 \\
\hline$>1$ disability & 71 & 43.03 \\
\hline \multicolumn{3}{|l|}{ History of birth delivery } \\
\hline Signs of abnormality during pregnancy & 42 & 25.45 \\
\hline \multicolumn{3}{|l|}{ History of birth delivery } \\
\hline Natural Birth & 112 & 67.88 \\
\hline Medical intervention (surgery, C-Section, forceps) & 53 & 32.12 \\
\hline \multicolumn{3}{|l|}{ Gestational age at birth } \\
\hline$<37$ week & 38 & 23.03 \\
\hline$\geq 37$ week & 127 & 76.97 \\
\hline \multicolumn{3}{|l|}{ Newborn weight (gr) } \\
\hline$<2500 \mathrm{gr}$ & 23 & 13.94 \\
\hline$\geq 2500 \mathrm{gr}$ & 142 & 86.06 \\
\hline Asphyxia at birth & 28 & 16.97 \\
\hline \multicolumn{3}{|l|}{ Family Information } \\
\hline \multicolumn{3}{|l|}{ Number of children } \\
\hline 1 child & 29 & 17.58 \\
\hline 2 child & 100 & 60.61 \\
\hline$\geq 3$ child & 36 & 21.82 \\
\hline Family with PWD & 24 & 14.55 \\
\hline \multicolumn{3}{|l|}{ Number of generations } \\
\hline$\leq 3$ generation & 87 & 52.73 \\
\hline$>3$ generation & 78 & 47.27 \\
\hline \multicolumn{3}{|l|}{ Household economics } \\
\hline Poor & 8 & 4.85 \\
\hline Not poor & 157 & 95.15 \\
\hline \multicolumn{3}{|l|}{$\begin{array}{l}\text { Interested in/Attention to monitoring signs of abnor- } \\
\text { mality and receiving information disability and dis- } \\
\text { ability detection }\end{array}$} \\
\hline \multicolumn{3}{|l|}{ Interested in monitoring signs of abnormality } \\
\hline Yes & 145 & 87.87 \\
\hline
\end{tabular}

\begin{tabular}{|l|c|c|}
\hline No & 20 & 12.12 \\
\hline $\begin{array}{l}\text { Have received information about disability and dis- } \\
\text { ability detection }\end{array}$ & 76 & \\
\hline Have received & 89 & 53.06 \\
\hline Never & 93.93 \\
\hline \multicolumn{2}{|c|}{ Table 1: Demographic Information of study participants ( $\mathrm{n}=165)}$. \\
\hline
\end{tabular}

The questionnaire for families consisted of 37 questions to help identify different types of disability (mobility, speaking and hearing, vision, intellectual, mental and others). Questions were designed for "Yes" and "No" answers. Participants only need to tick (x) in the most appropriate column to the best of their knowledge. If there were "Yes" answers, the child with disability was added to a list for disability screening.

The question guide for interviewing mothers of children with disability was developed with three main content areas: biographical information about families (household economic situation, number of generations living in the family, number of children in family, and number of children with disability in the family); information about the mother (age, ethnic minority, education, job, age landmarks for disability identification and detection, provision of information on early identification of disability, attitudes towards early identification of disability ...), and information about children with disability (age, gender, type of disability, causes of disability and birth order in family).

\section{Definitions and inclusion criteria}

Disability Definition: the study used the definitions and disability classification regulated in the Vietnam National Law on Disability: "Person with disabilities means a person who is impaired in one or more body parts or suffers functional decline manifested in the form of disability which causes difficulties in his/her work, daily life and study" [24].

Forms of Disability: following the National Law on Disability including mobility disability, speaking and hearing disability, visual disability, mental disability, intellectual disability and other disabilities [24].

Timepoints for disability detection and identification: We describe the process disability identification-diagnosis process in a child with disabilities over 5 timepoints that are equivalent to the age of the child at that time. That is: the time that children are identified as having a first sign of abnormality; the time that families share with surrounding people the disability situation of their children; the time when children were taken out for a disability check-up and screening; and the time when children were identified and diagnosed with disability by professionals. This process is called a disability identification-diagnosis process with the timepoints referred to as: identification, discussion, confirmation, check up and diagnosis.

\section{Data management and analysis}

Completed questionnaires were checked and cleaned at the interview sites and inputted into the EPIDATA software. The data was processed and analyzed by SPSS18.0. The statistical findings described an identification-diagnosis process in children with disabilities reported by their parents and roles of related stakeholders in this process. However, when doing factor correlation analysis, priority was given 
to analyse the factors relating to the timepoints for identifying and diagnosing disability as it is important for early disability detection and also because the timepoints of discussions, confirmation and check-up are strongly linked with the timepoints of identification and diagnosis of disability. We used the model of hierarchical regression analysis to identify factors relating to the two timepoints mentioned above in four main groups and blocks. Group one included four variables (household economy, number of children, number of generations living in one family, and the number of children with disability). Group two was mothers' information, including nine variables (age, ethnic minority, education, occupation and marital status, observation on signs of abnormality of children, discussions with health professionals about the signs of abnormality, and receiving information about the early identification and detection of disability). Group three included information about the children with disability, including 14 variables relating to the history of obstetrics during the mother's pregnancy (health problems of mothers during pregnancy such as having flu, fever, accident, and other variables on birth delivery such as normal birth delivery, asphyxia at birth, premature birth, birth weight under 2500 grams), and variables on the biological characteristics of the child (such as, gender, age and causes of disability) and related variables relating to forms of disability (mobility disability, speaking and hearing disability, visual disability, mental disability, intellectual disability and other disabilities), Group four was the timepoint of identifying the abnormality.

In the model relating to the timepoints for identifying abnormality, only variables in the first three groups were included, and a variable on "first person that parents discussed their child's abnormality is health staff" was excluded because this variable was not appropriate. As for group four, all timepoints on the process of identification and diagnosis of disability (identification, discussion, confirmation, check up, and diagnosis) were included in the model and the relation among these variables was strongly associated (correlation coefficient $>0.7$, even $>0.9$ ). Therefore, the variable on timepoint "identifying the abnormality" was included in the model. These groups of variables were included in the model following this order: family information, mothers' information, and information about timepoints of disability identification. Based on the analysis of the results, all variables with $p>0.05$ as the highest and the absolute value of the smallest Beta (B) were excluded until the model became significant (ANOVA with $\mathrm{p}<0.05$ ), and all independent variables contributed to the model having the statistical significance of $p \leq 0.05$. Two dependent variables were included in the model, including age points of identifying the first abnormality and the timepoints of children being confirmed and diagnosed.

Ethical considerations (ethical approval, informed consent procedure, use of incentives, etc.), Hanoi University of Public Health Human Research Ethics Committee has approved this study following the Decision 042/2014/YTCC-HD3 on 11/3/2014.

\section{Key Findings}

\section{Timepoints of a identification and diagnosis process}

Table 2 shows that children first started to be suspected as having an abnormality when they were 12.3 months old, and the abnormality was confirmed when 14.6 months old. Parents shared their worry with other people about their children's abnormality when the children were 14.1 months old. However, children were usually taken to the health clinics six months later for the first time (when they were 20.3 months old) and it took another three months for the children to be diagnosed and their disability confirmed at the professional health clinics (when children were 23.3 months old). So it takes at least 11 months, from the time the family starts to suspect a disability to the time children are confirmed as having a disability.

As for each form of disability, compared with the average timepoints of all the study population, mobility disability was suspected in the earliest timeframe (3.7 months old) compared to other forms of disability, and was confirmed as a disability when the children were 10.4 months old. This is a significant difference of $p<0.001$. Other forms of disability were suspected in a similar timeframe with the average timepoints of all the study population, but those children with other disabilities such as intellectual disability had an earlier timepoint of identification and diagnosis compared to the average timepoint $(\mathrm{p}<0.05)$. Children with congenital disability had earlier timepoints of the first suspicion of disability (at 10 months old) $(\mathrm{p}<0.05)$ but the timepoint for the diagnosis and confirmation is not different from that of the study population (Table 2).

Results of comparing the timepoint of identification-diagnosis (from the timepoint for suspicion of abnormality sign to diagnosis and confirmation) indicated that children with mobility disability, intellectual disability and other forms of disability had a shorter time for identification and diagnosis than that of the study population (6.7 months; 6.1 months and 4.8 months respectively), although the gap in time between identification and diagnosis was smallest (4.8 months) and a difference in time from the point of suspicion to diagnosis and confirmation still existed $(p<0.05)$. This means that children with disability did not have access to the early disability identification and detection services, even though children were suspected of having signs of disability.

\section{Roles of families and stakeholders in a disability identifica- tion-diagnosis process}

A disability identification - diagnosis process of CWD's usually follows these timepoints: the time that children are identified as having a first sign of abnormality; the time that families share their concern about the disability situation of their children with surrounding people; the time that children are taken for a disability check-up and screening; and the time that children are diagnosed with disability by professionals. The persons relating to these timepoints show their role in the process of disability identification and diagnosis. Results in table 2 show that it is mainly parents $(72.73 \%)$, who is the first persons detecting the first sign of child abnormality. Sharing with health staff about child abnormality occupies the biggest percentage among parents with CWD's (36.97\%) and then followed by with themselves $(33.3 \%)$. Health professionals who were the first to confirm signs of abnormality for children occupy the highest rate among cases $(47.88 \%)$ while it is mainly parents who decide to take their children for a disability check-up $(65.45 \%)$. This implies that parents and health professionals play important roles in the disability identification-diagnosis process in children with disabilities.

\section{Analysis of the correlation factors}

\section{Factors related to the timepoints for identification of signs of ab- normality in children}

In order to identify factors relating to the timepoints for identifying signs of abnormality in children with disability, we used hierarchical 
Citation: Thuy NTM, Cat TQ, Chut NH, Hung DC, Le NV (2020) A Process for Early Detection and Early Identification of Disability in Children Under Six Years of Age and other Related Factors. J Phys Med Rehabil Disabil 6: 044.

regression analysis with dependent variables, including the timepoint (age) to identify signs of abnormality and other independent variables included three groups as aforementioned, such as, family information, information about mothers and information about children. The independent variables have been presented in the data management and analysis section. When the four variables of the family information are included in Block 1, the results indicate that the variable "having person with disability in the family" and the variable "generations living in the family" has a statistical relationship with the timepoint of identifying signs of abnormality $(p<0,05)$. When the 9 variables of mothers' information were included in Block 2 of the model, the results indicate that only the variable "receiving information about early disability identification" had a meaningful relationship. Other variables of Block 1 (family information) still had a meaningful relationship with dependent variables $(p<0.05)$. When the 14 variables of Block 3 were included in the group of children's information, only three variables had a meaningful relationship with $p<0.05$ and these variables were "age", "congenital disability" and "mobility disability". However, the two variables of Block 1 no longer had a relationship with the model; thus, none of variables of this group had a relationship with the model.

So, only two out of three groups of information were included in the model and four variables had a relationship with the timepoint of identifying signs of abnormality in children with disability, including "receiving information about the early identification of disability" ( $<<0.05)$, "age", "congenital disability" and "mobility disability" $(p<0.001)$. Results in table 3 show that there were three negative correlation variables and a positive correlation variable on the timepoint of identifying signs of abnormality. This means that if mothers received information about early identification of disability, children got congenital disability and mobility disability, the timepoint for identifying signs of abnormality would be earlier and vice versa-the older the children were identified with signs of abnormality, the later their disability was confirmed.
The explain ability of the model reached $34.9 \%$ in which the variable "receiving information about the early identification of disability" contributed $6.4 \%$ and the remaining three variables contributed $28.5 \%$.

In reviewing the absolute value of the standardized Beta coefficient it is recognized that the "age" variable had the biggest value and therefore, would be the variable with the most predictive value to the model. Following this was the variable "mobility disability" and "congenital disability" and finally the variable "receiving information about the early identification of disability".

\section{Several factors related to the timepoint of a child being diagnosed with a disability}

Early diagnosis helps children to get early intervention. Therefore, determining the factors related to the time the child is diagnosed and identified as having a disability is very important. Similar to factors related to the timepoint of a child being diagnosed, hierarchical multiple regression analysis was used with dependent variables, including the timepoint (age) of detecting and identifying and other independent variables were applied into the model in 4 blocks: family information, mother's information, children's information and timepoints for detecting signs of abnormality. These independent variables were covered in the section data management and analysis. In the first block, "household economics" was the only variable in the four variables having a statistical relationship at the timepoint a child was detected with a sign of abnormality $(\mathrm{p}=0.04)$. When 9 independent variables were included in the group of "mothers' information" in Block 2 of the model, only two variables including "first person that parents discussed their children's sign of abnormality with was health staff" $(\mathrm{p}=0.000)$ and "receiving information about early disability identification" ( $p=0.037$ ) had a meaningful relationship with the dependent variables.

\begin{tabular}{|c|c|c|c|c|c|c|c|c|c|c|}
\hline \multirow{2}{*}{ Content } & \multicolumn{2}{|c|}{ Father/Mother } & \multicolumn{2}{|c|}{ Close persons } & \multicolumn{2}{|c|}{ Kindergarten teachers } & \multicolumn{2}{|c|}{ Health staff } & \multicolumn{2}{|c|}{ Not recall/no reply } \\
\hline & $\mathrm{n}$ & $\%$ & $\mathrm{n}$ & $\%$ & $\mathrm{n}$ & $\%$ & $\mathrm{n}$ & $\%$ & $\mathrm{n}$ & $\%$ \\
\hline First person detecting abnormality & 120 & 72.73 & 19 & 11.52 & 3 & 1.82 & 23 & 13.94 & 0 & 0 \\
\hline $\begin{array}{l}\text { First person that parents discussed their children's sign } \\
\text { of abnormality with }\end{array}$ & 55 & 33.33 & 44 & 26.67 & 5 & 3.03 & 61 & 36.97 & 0 & 0 \\
\hline First person to confirm children's sign of abnormality & 70 & 42.42 & 10 & 6.06 & 3 & 1.82 & 79 & 47.88 & 3 & 1.82 \\
\hline Person who thinks children should be checked & 108 & 65.45 & 8 & 4.85 & 0 & 0 & 49 & 29.7 & 0 & 0 \\
\hline
\end{tabular}

Table 2: Roles of stakeholders in a disability identification for under 6 years old children.

\begin{tabular}{|c|c|c|c|c|c|}
\hline \multirow{2}{*}{ Variable } & \multicolumn{2}{|c|}{ Unstandardized Coefficients } & \multirow{2}{*}{$\begin{array}{c}\text { Standardized Coefficients } \\
\text { Beta }\end{array}$} & \multirow{2}{*}{$95 \%$ CI for B } & \multirow{2}{*}{$\mathbf{p}$} \\
\hline & $\mathrm{B}$ & SE & & & \\
\hline \multicolumn{6}{|l|}{ Model 1 - Mother's factors } \\
\hline Receive information about early disability detection & -6.622 & 1.979 & -0.253 & $-10.530-(-2.713)$ & 0.001 \\
\hline \multicolumn{6}{|c|}{$\mathrm{B}_{0}=15.33 ; \mathrm{R}=0.253 ; \mathrm{R}^{2}=0.064 ; \mathrm{R}_{\text {adjusted }}^{2}=0.059 ; \mathrm{R}_{\text {change }}^{2}=0.064 ; \mathrm{F}=11.19 ; \mathrm{p}=0.001$} \\
\hline \multicolumn{6}{|l|}{ Model 2 - Children's factors } \\
\hline Receive information about early disability detection & -3.664 & 1.704 & -0.140 & $-7.029-(-0.299)$ & 0.015 \\
\hline Age & 0.227 & 0.051 & 0.307 & $0.126-0.327$ & 0.000 \\
\hline Congenital disability & -7.115 & 1.942 & -0.236 & $-10.949-(-3.280)$ & 0.000 \\
\hline Mobility disability & -7.437 & 2.008 & -0.256 & $-11.402-(-3472)$ & 000 \\
\hline
\end{tabular}

Table 3: Hierarchical multivariate regression model on related factors of timepoints for detecting signs of abnormality of children with disability ( $\mathrm{n}=165$ ). 
In the third block- "children's information", only the "age" variable and "intellectual disability" had a meaningful relationship with the model $(\mathrm{p}<0.05)$ while "household economics" in the first block and the variable "receiving information about early disability identification" in the second block, no longer had any relationship with the model ( $p>0.05$ ). This meant that group one (family information) had no variable relating to the model. Finally, when the variable "timepoint to detecting the sign of abnormality" was introduced to the fourth block of the model, all remaining variables still had a relationship with the model.

So, only three out of four groups of information with four variables related to the timepoint for identification of disability in children with disability. These variables included "first person that parents discussed their children's sign of abnormality with was health staff" in the mother's information group $(\mathrm{p}=0.015)$, "age" and "intellectual disability" in the children with disability information group $(\mathrm{p}=0.000)$ and "timepoint for detecting signs of abnormality". The results in table 4 indicate there are two negatively correlated variables and two are positively correlated with the time of diagnosis. This meant that if parents chose to discuss with health staff their children's sign of abnormality or if children had intellectual disability, children would be identified with disability earlier. In contrast, if children are older and/or there is a later timepoint for detecting signs of abnormality, then children would be diagnosed and identified with disability later. The explainability of the model reached $54.8 \%$, of which the variable "first person that parents discussed their children's sign of abnormality with was health staff" contributed $7.6 \%$ and other variables including "age" and "intellectual disability" contributed $30.7 \%$ and the variable "timepoint for detecting signs of abnormality" contributed $17.5 \%$. Considering the absolute value of the beta efficiency, the results indicate that the variable "timepoint for detecting sign of abnormality" has the greatest value: therefore, this variable has maximum predictive value for the model. Following was the "age" variable and "first person that parents discussed their children's sign of abnormality with was health staff" variable and finally the "intellectual disability" variable.

\section{Discussion}

\section{Timepoints of a disability identification-diagnosis process in children with disability}

Timepoints of a disability identification and diagnosis process in general

A timepoint for identifying a first sign of abnormality in this study was earlier than the same findings in a study conducted in Vietnam in 2015, which found that the average timepoint for identifying a first sign of abnormality was 2.56 years old, equivalent to more than 30 months [12]. However, the findings in this study were higher than that of a national study conducted in the United States regarding early intervention during 1997-1998. This US study was conducted on fewer than 31 months old children [15]. In this study, parents started to worry about their children's development at an average age of 7.4 months and the timepoint for being diagnosed and identified with disability was 8.8 months, only one month later than the timepoint for detecting signs of abnormality. This means that children under 31 months old in the US were diagnosed and identified right after they were suspected with a sign of abnormality, while it took two months for children in our study to be confirmed with a sign of abnormality (14.6 months compared to 13.2 months old) and it took six months after that for children to be taken to the health clinic for the first time for a disability check-up (23.3 months compared to 20.3 months) and another three months for children to be diagnosed and identified with disability by health professionals (23.3 months compared 20.3 months, table 5). On average, it took 11 months for children in this study to be detected with a first sign of abnormality until the timepoint they were diagnosed and identified with disability. This timeframe was 10 times longer than that identified in the US study. So, in our study, we identified a delay in identifying signs of abnormality, a delay in accessing health services (disability check-up for the first time at the health clinic) and a delay in access to professional and speciality health services (children being diagnosed with disability).

\begin{tabular}{|c|c|c|c|c|c|}
\hline \multirow{2}{*}{ Variable } & \multicolumn{2}{|c|}{ Unstandardized Coefficients } & \multirow{2}{*}{$\begin{array}{c}\text { Standardized Coefficients } \\
\text { Beta } \\
\end{array}$} & \multirow{2}{*}{$95 \%$ CI for B } & \multirow{2}{*}{$\mathbf{p}$} \\
\hline & $\mathbf{B}$ & SE & & & \\
\hline \multicolumn{6}{|l|}{ Model 1 - Mother's factors } \\
\hline $\begin{array}{l}\text { First person that parents discussed their children's sign } \\
\text { of abnormality with was health staff }\end{array}$ & -10.658 & 2.912 & -0.276 & $-16.408-(-4.907)$ & 0.000 \\
\hline \multicolumn{6}{|c|}{$\mathrm{B}_{0}=27.556 ; \mathrm{R}=0.276 ; \mathrm{R}^{2}=0.076 ; \mathrm{R}_{\text {adjusted }}^{2}=0.07 ; \mathrm{R}_{\text {change }}^{2}=0.076 ; \mathrm{F}=71.73 ; \mathrm{p}=0.000$} \\
\hline \multicolumn{6}{|l|}{ Model 2 - Children's factors } \\
\hline $\begin{array}{l}\text { First person that parents discussed their children's sign of } \\
\text { abnormality with was health staff }\end{array}$ & -9.090 & 2.401 & -0.235 & $-13.381-(-4.350)$ & 0.000 \\
\hline Child's age & 0.567 & 0.067 & 0.528 & $0.435-0.698$ & 0.000 \\
\hline Intellectual Disability & -6.393 & 2.569 & -0.154 & $-11.467-(-1.320)$ & 0.014 \\
\hline Physical disability & -7.437 & 2.008 & -0.256 & $-11.402-(-3472)$ & 000 \\
\hline \multicolumn{6}{|c|}{$\mathrm{B}_{0}=6.572 ; \mathrm{R}=0.619 ; \mathrm{R} 2=0.383 ; \mathrm{R} 2$ adjusted $=0.372 ; \mathrm{R} 2$ change $=0.307 ; \mathrm{F}=40.11 ; \mathrm{p}=0.000$} \\
\hline \multicolumn{6}{|l|}{ Model 3 - Disability of Children } \\
\hline $\begin{array}{l}\text { First person that parents discussed their children's sign of } \\
\text { abnormality with was health staff }\end{array}$ & -6.583 & 2.088 & -0.170 & $-10.706-(-2.460)$ & 0.002 \\
\hline Child's age & 0.351 & 0.064 & 0.327 & $0.225-0.478$ & 0.000 \\
\hline Intellectual Disability & -6.509 & 2.207 & -0.157 & $-10.867-(-2.152)$ & 0.004 \\
\hline Timepoint for detecting signs of abnormality & 0.668 & 0.088 & 0.459 & $0.495-0.841$ & 0.000 \\
\hline
\end{tabular}


Citation: Thuy NTM, Cat TQ, Chut NH, Hung DC, Le NV (2020) A Process for Early Detection and Early Identification of Disability in Children Under Six Years of Age and other Related Factors. J Phys Med Rehabil Disabil 6: 044.

\begin{tabular}{|c|c|c|c|c|c|c|c|}
\hline \multirow{4}{*}{ Content } & $\begin{array}{c}\text { Indentify } \\
\text { abnormality (1) }\end{array}$ & $\begin{array}{l}\text { Discuss with } \\
\text { others (2) }\end{array}$ & $\begin{array}{c}\text { Confirm children } \\
\text { with abnormality (3) }\end{array}$ & $\begin{array}{l}\text { First time being taken } \\
\text { to health clinic (4) }\end{array}$ & $\begin{array}{l}\text { Children being diagnosed with } \\
\text { disability at health clinics (5) }\end{array}$ & $\begin{array}{l}\text { Average difference } \\
\text { (1\&5) }\end{array}$ & \\
\hline & mean \pm sd & mean \pm sd & mean \pm sd & mean \pm sd & mean \pm sd & mean \pm sd & $\mathrm{P} * *$ \\
\hline & $(\min -\max )$ & $(\min -\max )$ & $(\min -\max )$ & $(\min -\max )$ & $(\min -\max )$ & $(\min -\max )$ & \\
\hline & $(\mathrm{p}) * *$ & & & & $(\mathrm{p})^{*}$ & $(\mathrm{p})^{*}$ & \\
\hline \multirow{3}{*}{ General } & $12.28 \pm 13.06$ & $14.12 \pm 14.06$ & $14.64 \pm 14.57$ & $20.34 \pm 18.65$ & $23.29 \pm 19.01$ & $11.01 \pm 14.68$ & 0 \\
\hline & $(0.00-60.00)$ & $(1.00-60.00)$ & $(1.00-60.00)$ & $(1.00-66.00)$ & $(1.00-66.00)$ & $(0.00-57.00)$ & \\
\hline & $(-)$ & & & & $(-)$ & $(-)$ & \\
\hline \multicolumn{8}{|c|}{ Forms of disability } \\
\hline \multirow{3}{*}{ Physical } & $3.7 \pm 4.56$ & $5.41 \pm 6.39$ & $6.09 \pm 6.91$ & $6.57 \pm 7.39$ & $10.43 \pm 11.97$ & $6.74 \pm 11.54$ & 0 \\
\hline & $(0.00-20.00)$ & $(1.00-24.00)$ & $(1.00-24.00)$ & $(1.00-30.00)$ & $(0.00-48.00)$ & $(0.00-45.00)$ & \\
\hline & 0 & & & & 0 & -0.016 & \\
\hline \multirow{3}{*}{$\begin{array}{l}\text { Speakin-Hear- } \\
\text { ing }\end{array}$} & $13.01 \pm 11.22$ & $14.47 \pm 11.34$ & $14.99 \pm 11.97$ & $20.45 \pm 17.45$ & $24.2 \pm 17.98$ & $11.18 \pm 14.56$ & 0 \\
\hline & $(1.00-60.00)$ & $(1.00-60.00)$ & $(1.00-60.00)$ & $(1.00-61.00)$ & $(1.00-61.00)$ & $(0.00-48.00)$ & \\
\hline & -0.542 & & & & -0.638 & -0.911 & \\
\hline \multirow{3}{*}{ Visual } & $11.05 \pm 15.76$ & $14.82 \pm 17.79$ & $15 \pm 18.44$ & $22.5 \pm 21.03$ & $25.76 \pm 21.35$ & $14.71 \pm 17.95$ & 0 \\
\hline & $(0.00-60.00)$ & $(1.00-60.00)$ & $(1.00-60.00)$ & $(1.00-66.00)$ & $(0.00-66.00)$ & $(0.00-57.00)$ & \\
\hline & -0.582 & & & & -0.417 & -0.115 & \\
\hline \multirow{3}{*}{ Intellectual } & $12.02 \pm 11.24$ & $13.04 \pm 11.19$ & $14.02 \pm 12.11$ & $15.2 \pm 12.9$ & $18.1 \pm 14.54$ & $6.08 \pm 10.35$ & 0 \\
\hline & $(1.00-50.00)$ & $(1.00-50.00)$ & $(1.00-50.00)$ & $(1.00-54.00)$ & $(1.00-54.00)$ & $(0.00-45.00)$ & \\
\hline & -0.872 & & & & -0.016 & -0.002 & \\
\hline \multirow{3}{*}{ Mental } & $17.63 \pm 13.58$ & $20.06 \pm 15.82$ & $20.48 \pm 16.37$ & $26.06 \pm 20.41$ & $28.38 \pm 19.46$ & $10.75 \pm 12.78$ & 0.004 \\
\hline & $(1.00-47.00)$ & $(1.00-48.00)$ & $(1.00-48.00)$ & $(1.00-65.00)$ & $(1.00-65.00)$ & $(0.00-32.00)$ & \\
\hline & -0.136 & & & & -0.312 & -0.936 & \\
\hline \multirow{3}{*}{ Others } & $9.64 \pm 15.22$ & $10.49 \pm 15.86$ & $10.57 \pm 15.81$ & $13.29 \pm 17.64$ & $14.46 \pm 17.55$ & $4.82 \pm 10.08$ & 0.028 \\
\hline & $(1.00-54.00)$ & $(1.00-54.00)$ & $(1.00-54.00)$ & $(1.00-54.00)$ & $(1.00-55.00)$ & $(0.00-33.72)$ & \\
\hline & -0.404 & & & & -0.022 & -0.006 & \\
\hline \multicolumn{8}{|l|}{ Causes } \\
\hline \multirow{3}{*}{$\begin{array}{c}\text { Congenital } \\
\text { disability }\end{array}$} & $10.03 \pm 12.28$ & $12.12 \pm 13.50$ & $12.54 \pm 14.12$ & $17.54 \pm 17.56$ & $21.20 \pm 18.46$ & $11.17 \pm 15$ & 0 \\
\hline & $(0.00-60.00)$ & $(1.00-60.00)$ & $(1.00-60.00)$ & $(1.00-66.00)$ & $(1.00-66.00)$ & $(0.00-57.00)$ & \\
\hline & -0.043 & & & & -0.209 & -0.825 & \\
\hline \multirow{3}{*}{$\begin{array}{l}\text { Acquired } \\
\text { disability }\end{array}$} & $19.10 \pm 13.11$ & $20.18 \pm 14.13$ & $21.01 \pm 14.19$ & $28.80 \pm 19.49$ & $29.63 \pm 19.46$ & $10.53 \pm 13.83$ & 0 \\
\hline & $(1.00-50.00)$ & $(1.00-55.00)$ & $(1.00-55.00)$ & $(1.00-61.00)$ & $(1.00-61.00)$ & $(0.00-48.00)$ & \\
\hline & -0.02 & & & & $\begin{array}{l}-0.043 \\
\end{array}$ & -0.906 & \\
\hline
\end{tabular}

Table 5: Average age of children with disability through timepoints of disability identification-diagnosis process based on the forms of disability and its causes.

With a delay in identifying and confirming signs of abnormality, parents were likely to discuss with other people the situation of their children and discussions with others confirmed for parents that their children had an abnormality. This indicated that parents did not have knowledge about early disability detection and identification and thus they were not confident and had to consult with the other people to confirm their suspicion.

A study on the knowledge of carers for children under three years in Quynh Phu, Thai Binh province indicated that only $17.7 \%$ of carers had knowledge about early disability detection [25]. The delay in access to first health services can be explained by lack of services, difficulty of access to services, no information about the services, costly services or difficulty in travel. These are the first causes identified by the majority of studies [26-29]. However, in Vietnam, the lack of access to health services for people with disability was mainly due to the lack of information about the necessary services [30]. Other reason was because parents were afraid of discrimination if there were people with disability in their families and they wanted to hide this [31]. These were also reasons relating to attitudes towards disability and this caused parents of children with disability not to access health services early after they detected their children's abnormality [32]. As for the delay in access professional and speciality health services, the first reason was because of parents and even health staff, lacking information about professional and speciality health services with regard to disability detection and identification. A study conducted by Vo Song Ha et al., revealed challenges in disability detection and identification were a result of lack of guidelines in assessment and limited communication among health staff and parents of children [33].

So delays in the disability identification-diagnosis process related to parents and health staff included: parent's lack of knowledge about disability detection; negative attitudes towards people with disability; a lack of information about related services on diagnosis and identification of disability; the unavailability of disability speciality services and/or a lack of information about these services among health staff. These are the main reasons for delays in disability detection and identification at the health clinics. These findings were similar to the findings in another study conducted by Christensen 
et al., [34] that the difference in the rate and ages of disability detection and identification among different localities were due to differences in cost and service availability in the different localities [34]. Christensen's study was conducted in Hanoi, where the socio-economic conditions and services were better than those in other regions of the country. Therefore, children with disability in other regions of Vietnam might face more difficulties in disability detection and identification. In other words, children in more disadvantaged and difficult regions could be detected and identified with disability later. These matters will be discussed in a following section.

\section{Timepoints of a disability type based process for detection and diagnosis of disability}

Table 5 indicates that at the timepoint when suspicion starts that there are signs of abnormality in children, it is only children with physical disabilities who are considered to be detected with disability "early" ("early" was used to compare with the common data of all study participants with $\mathrm{p}<0.05$ ). This might be because the sample size was small and it was difficult to identify and assess the differences. If "causes" are used as the criteria for assessment, congenital disability were detected with "signs of abnormality" earlier (children were under 10 months old), and acquired disability was detected later at a meaningful level $(p<0.05)$. At the timepoint when a child was diagnosed with disability, only mobility disability was diagnosed early $(\mathrm{p}<0.001)$ while intellectual disability and other forms of disability were diagnosed quite later $(p<0.05)$. However, these three forms of disability were detected and diagnosed in a shorter timeframe $(\mathrm{p}<0.05)$, from 4.8 to 6.7 months, while the average timeframe for detection and diagnosis was 11 months. This finding indicates that sensory disabilities (hearing and vision) and mental disabilities were not paid enough attention. The result was that children under six years old were detected and diagnosed later for these sensory disabilities. This means that, different forms of disability were detected and diagnosed within different timepoints. These findings were similar to other studies and documents on early disability detection and identification and these will be presented in the following section.

A study of Yoshiaki comparing the needs of children with autism disorder in Vietnam, Japan and China revealed that most Japanese children were detected with signs of abnormality on development or sign of disability at a timepoint of 9-10 months, but were diagnosed and identified with disability at three years old, while the age for detecting the first sign of abnormality in China and Japan was 1.5 years old, with diagnosis and identification at two years [14]. Autism disorder was included in the group of other forms of disability according to the National Disability Law of Vietnam [24]. According to the results presented in table 5, the age for detecting this form of disability was 9.6 months and was diagnosed and identified at 14.5 months, similar to the data of Japan but earlier than results in Vietnam in the same study. This means that after five years (our study was conducted in 2016); children with autism disorder were detected and diagnosed earlier in Vietnam.

Joshua R Mann et al., [22] conducted a study of 5,358 children with slow development using MEDICAID in South Carolina, the United States, in order to identify the ages at which children having developmental disorder were diagnosed and identified. The findings indicated that African-American children were diagnosed at an age of 4.08 years and white American children were diagnosed at the age of 4.27 years old. Children with developmental disorders usually had intellectual disability diagnosed at the age of 2.6 years old and children with cerebral palsy (bai nao) were being diagnosed at the age of 2.1 years [22]. Therefore, Mann's study had similar findings to those in our study, in that children with mobility disability were diagnosed earliest (children with cerebral palsy were in the group of mobility disability) and children with slow intellectual development were being diagnosed earlier compared to overall study participants. However, the average age point at which children with developmental disorders were diagnosed was much older than that identified in our findings ( 4.08 and 4.27 years old and 27 months old). This could be explained by the difference in the time of the study and study participants. A study was conducted by Joshua R. Mann 10 years ago on children who were beneficiaries of MEDICAID (a US government health care support program provided to those who have low income and were in disadvantaged and difficult conditions, including children and adults with disability, the elderly and pregnant women). Those MEDICAID beneficiaries were considered to have limited access to health care services. Therefore it is understandable that their children were detected with developmental disorders late. In our study, up to $5 \%$ of the participants came from poor families, thus the difference in age of being detected and diagnosed with disability can be explained. This also indicated that the more difficult the conditions the children with disability were in, the later they were detected and identified with disability.

As for children with hearing and speech impairments in our study, the timepoint for detecting signs of abnormality was 13 months and the timepoint for being diagnosed and identified with disability was 24.2 months. Compared with a study conducted in Tehran, the capital of Iran (where, on average, it took 12.6 months for detection and 15.2 months for diagnosis), children with disability in our study had a similar timepoint for disability detection but a later timepoint for diagnosis and identification [16]. However, studies in Haiphong province on the timepoints for detection and diagnosis of disability were 21.3 months and 30.4 months respectively [18] and children with hearing and speech impairments were detected and diagnosed earlier. This study also discovered children with hearing impairment who lived in the centre of the city were detected, diagnosed and used hearing assistive devices much earlier than those living further from the centre. This finding could explain the difference in the timepoints of disability detection and diagnosis for children with hearing impairment in the two studies conducted in two different regions of Vietnam (Hanoi and Haiphong) and this also confirmed that children with disability living in disadvantaged locations were detected and diagnosed later.

\section{Timepoints of a cause based process for disability detec- tion and diagnosis}

Due to the small sample size, we did not divide the causes of disability into small groups, but only two main groups-congenital and acquired disability. Table 5 indicates that children with congenital disability had a timepoint for detection of signs of abnormality at 10 months, which is earlier than the average timepoint of the study population (12.3 months, $p<0.05)$, while children with acquired disability were detected later $(19.1$ months, $\mathrm{p}<0.05)$ and the time for being diagnosed was also later (29.6 months and 23.3 months, $p<0.05$ ). However, the timeframe between detection and identification was the same and this finding was also similar to that of the total participants (11 months) (Table 5). This indicated that children with acquired disability were 
not taken for diagnosis and identification of disability early, meaning that diagnosis and identification of disability were both carried out late.

\section{Roles of Family and Stakeholders in a Disability Identification-Diagnosis Process}

This study indicated that the father/mother were usually the first people to detect signs of abnormality in their children $(72.7 \%)$, similar to the findings of studies conducted in Japan, Vietnam and China. Of the parents it was mainly mothers who detected a child's disability (61\%-72\%) with fathers playing a lesser role (6.5-9\%) [14]. A study conducted in Illinois indicated that the father/mother is the first people detecting a child's disability [17]. Thus it is recognized that parents play the most important role in early detection of disability in children.

Table 2 indicates that while parents account for a high rate in detecting disability/signs of abnormality and deciding to take a child for disability identification, health staff account for a high rate in being involved in discussions about a child's signs of abnormality and in confirming a child's abnormality. This indicates that the interaction between parents and health staff is important in encouraging parents to take their child for disability diagnosis and identification. If the interaction between healthcare staff and parents is weak, children would be diagnosed with disability late [33] and therefore children would have late intervention.

The findings of the study also showed that only $1.8 \%-3 \%$ of kindergarten teachers participated in a disability identification-diagnosis process, similar to the findings in a study conducted by Yoshiaki Takeuchi et al., in which only $3.2 \%$ children in Vietnam were informed by teachers about their suspicion of the disability or sign of abnormality [14]. It seems teachers did not feel compelled to pursue their tasks on early disability detection because assessment of children's development and consulting with the families were regular tasks [35-38].

Parents and health staff were the key stakeholders in this study having the main roles in disability detection and identification of children. This finding is also relevant to the average age of children being detected with signs of abnormality (only 12.3 months) and an average age for diagnosis was 23.3 months, which is before children have started going to kindergarten in Vietnam.

\section{Some Factors Related to Disability Detection and Identification of Children with Disability in Vietnam}

\section{Factor of age and form of disability}

Multi-variable analysis showed that the "age" variable related to both regression models: The timepoint for disability detection or signs of abnormality and the timepoint for disability diagnosis and identification, in which, if a child gets one month older, the timepoint for detecting abnormality/disability is 0.23 month later and the timepoint for diagnosis is 0.58 months later. This finding is similar to the finding identified in a study conducted by David S. Mandell in Pennsylvania (the timepoint for autism diagnosis was 0.2 years later when a child was 1 year older) [13]. A study conducted by Joshua R. Mann [22] considered a minority factor relating to the timepoint for diagnosis of developmental disorders and the findings indicated that the age of a child is a related factor having statistical meaning $(\mathrm{p}<0,05)$ and is related to the timepoint of developmental disorder diagnosis [22].
This finding is relevant to a child's developmental process. When a child gets older, more of his/her skills are developed and functioning and disability is more evident. Therefore, it is more difficult to detect disability when a child is very young, especially under one year old. At this time, it is family members and health staff who interact with children the most; therefore it is necessary to build capacity for them in disability detection and identification.

The variable "intellectual disability" had a relationship with the timepoint for disability diagnosis and identification in which a child with intellectual disability was diagnosed about 6 months earlier than children with other forms of disability (Table 4). This is relevant to the results presented in table 5 , in which the timepoint for diagnosis and the timeframe between detection - identification of this form of disability had a meaning compared to the whole study population (18 months, 23.3 months and 6.08 months and 11.01 months), while the timepoint for detecting abnormality was 12 months, similar to that for other forms of disability. Therefore, mothers with a child with disability paid good attention to take their child to the professional health clinics for disability diagnosis and identification. But why were these children not detected with signs of abnormality? It was probably because mothers did not have knowledge in detecting these forms of disability. In fact, a literature review of documents on intellectual disability screening for children conducted in 1999-2009 indicated there is no reliable tool for intellectual disability screening [39].

The variable "mobility disability" only had a relationship with the regression model on the timepoint for detecting abnormality in which children with mobility disability were detected with signs of abnormality 7.4 months earlier compared to other forms of disability. In other words, children with disability but not with a mobility disability were detected quite later with signs of abnormality. This might be because the mobility of a child gets more attention and therefore mobility disability was easier to be detected than other forms of disability. This assumption was relevant to the findings for the form of intellectual disability as described above, which was that diagnosis was done early but detection was not early. Therefore, it is important to improve knowledge of parents and related stakeholders in detecting not only mobility disability but also other forms of disability. However, the contribution of this variable to this model regarding detecting abnormality was only $5.6 \%$ (Table 3 ) and the model of the timepoint for detection and identification, with the variable "intellectual disability") contributes only $6.7 \%$ to the model (Table 4).

The variable "congenital disability" only had a relationship with the timepoint of detecting abnormality, in which children with congenital disability were detected 7.1 months earlier than those with acquired disability. This did not mean that acquired disability was detected 7 months later, but children acquired disability at later ages, therefore, the timepoint for detecting abnormality signs was late (19.1 months - later than the average age for detecting abnormality signs for all study participants, $p<0.05$, Table 5 ). Children with congenital disability would have early signs of abnormality so that they were detected early.

\section{Factor on receiving information about early detection and discussion of abnormality signs with health staff}

Results of data analysis showed that children whose mothers received information about early disability detection were detected as having abnormality signs 3.7 months earlier than those whose 
mothers did not receive the information (Table 3). This finding confirms that the provision of early disability detection information helped mothers detect abnormality signs in their child, who they then took for earlier disability diagnosis and identification. A study conducted in Hoai Duc by Nguyen Thi Minh Thuy indicated that mothers who were provided with information about early disability detection via training workshops took their children for disability diagnosis at a rate 1.49 times higher than those not provided with information [40]. Another study conducted in Thai Binh, Vietnam, on mother's knowledge of early disability detection revealed that the rate of those mothers who had access to information about early disability detection, having knowledge about early disability detection was 2.2 times higher. They also had a rate of practice in early disability detection 2.7 times higher than those mothers who did not have access to the information $[25,41]$. A study conducted on children with hearing impairment indicated that implementation of early detection and intervention programs for children with hearing impairment and community awareness-raising programs were effective measures for early detection of hearing impairment for children, ensuring the best development for children [18]. This again confirmed the role of awareness training programs and training workshops conducted for parents and carers on disability and early disability detection.

Findings of the study revealed that if parents of children with disability shared their suspicion about their children's abnormality signs with health staff, their children's disability would be diagnosed and identified 9 months earlier than those who only shared their suspicion with others but not with health staff. The implied need for capacity building should be met for local health staff in early disability detection and diagnosis. This is also relevant to an implication provided by a recent published study conducted in the United States on strengthening knowledge on autism, improving the situation of early autism detection in the localities [34].

\section{Factor on timepoint of detecting sign of abnormality}

The findings of this study indicated that if the timepoint for abnormality detection were one month later, children would be diagnosed 0.67 months later. This confirmed the importance of early detection of abnormality signs. The earlier disabilities were detected, the earlier the children were diagnosed with disability. Therefore, should there be intervention programs carried out for families and people close to the family and carers to help them in detecting abnormality early, then children would be diagnosed on time and finally they would receive intervention services and support from the Government. Theeranate $\mathrm{K}$ and Chuengchitraks $\mathrm{S}$, when comparing the results of detecting developmental issues of children (PEDS and Denver II), concluded that parent's worries about the development of their children was very important information for them to refer their children to necessary services. This was more predictive of the development and disability situations of children than disability screening tests [42].

\section{Study Limitations}

The sample size of this study was 165 children with all forms of disability. If children were grouped based on each form of disability, the groups would be too small, so that it was difficult for analyzing each form of disability. In addition, participants also included those with acquired disability - who did not have any disability until some problem happened to them and they became disabled. This meant the timepoint for detecting signs of abnormality was also not completely relevant, although we still had control over the model with multi-variables when identifying related factors. However, if we could do analysis for each group, the findings would have been more characteristic.

\section{Conclusion and Recommendations}

Children with mobility disability were detected earlier than those with other forms of disability. Similar to mobility disability, children with intellectual disability and acquired disability were detected earlier than those with sensory disability and mental disability. Families and health staff played important roles in the disability identification-diagnosis process for children with disability. Besides the factors of age, congenital disability, and mobility disability, related factors of mothers receiving information about early detection had a relationship with the timepoint for detecting signs of abnormality in children. Timepoints for children being diagnosed and identified with disability had a relationship with the timepoint for detecting signs of abnormality. Timepoints for children being diagnosed and identified with disability had a relationship with age, intellectual disability, the timepoint for detection of signs of abnormality and mother's discussions with health staff about their children's abnormality signs.

Findings in this study suggested that provision of information on early detection to mothers, especially information about detecting other forms of disability, not only mobility disability, and encouraging mothers discuss with health staff about signs of abnormality would help children with disability being diagnosed earlier. In addition, strengthening the capacity of staff working at health clinks about disability detection would help children to be detected and diagnosed with disability earlier.

\section{Implications}

This study contributes to early disability identification and intervention programs for children.

\section{Acknowledgements}

Our sincere thanks to Hoai Duc Health Clinic, Hanoi Capital, for their support in data collection, contacting participants for the study and coordinating all related study activities. This support has helped us achieve our study objective.

\section{References}

1. WHO (2011) World report on disabilities. WHO, Geneva, Switzerland.

2. General Statistics Office (2018) National survey on people with disabilities 2016. Statistical Publishing House, Hanoi, Vietnam.

3. Murphy NA, Christian B, Caplin DA, Young PC (2007) The health of caregivers for children with disabilities: Caregiver perspectives. Child Care Health Dev 33: 180-187.

4. Viana MC, Gruber MJ, Shahly V, Alhamzawi A, Alonso J, et al. (2013) Family burden related to mental and physical disorders in the world: Results from the WHO World Mental Health (WMH) surveys. Braz J Psychiatry $35: 115-125$.

5. Laskar AR, Gupta VK, Kumar D, Sharma N, Singh MM (2010) Psychosocial effect and economic burden on parents of children with locomotor disability. Indian J Pediatr 77: 529-533.

6. Caicedo C (2014) Families with special needs children: Family health, functioning, and care burden. J Am Psychiatr Nurses Assoc 20: 398-407. 
Citation: Thuy NTM, Cat TQ, Chut NH, Hung DC, Le NV (2020) A Process for Early Detection and Early Identification of Disability in Children Under Six Years of Age and other Related Factors. J Phys Med Rehabil Disabil 6: 044.

7. UNICEF (1999) Children with Disabilities: Major Cause and Consequences of Childhood Disability. In: Rasheed S (ed.). Education Update. UNICEF, New York, USA.

8. Chopra G (2011) Training community workers on early detection and management of children with disabilities in poor resource communities. Asia Pacific Regional Conference on ECD, Singapore.

9. UNICEF (2013) The state of the world's children 2013: Children with disabilities. UNICEF, New York, USA.

10. Institute of Medicine and National Research Council (2000) From Neurons to Neighborhoods: The Science of Early Childhood Development. The National Academies Press, Washington, DC, USA.

11. Markides A (1970) The speech of deaf and partially-hearing children with special reference to factors affecting intelligibility. Br J Disord Commun 5: 126-140.

12. Van Cong T, Weiss B, Toan KN, Le Thu TT, Trang NT, at al. (2015) Early identification and intervention services for children with autism in Vietnam. Health Psychol Rep 3: 191-200.

13. Mandell DS, Novak MM, Zubritsky CD (2005) Factors associated with age of diagnosis among children with autism spectrum disorders. Pediatrics 116: 1480-1486.

14. Takeuchi Y, Araki H, Araki M, Maeda A, Inoue Y, et al. (2011) Research on the Needs of Children with Autism Spectrum Disorder and Their Families: A Comparison of Japan, China and Vietnam.

15. Hebbeler K, Spiker D, Bailey D, Scarborough A, Mallik S, et al. (2007) Early Intervention for Infants and Toddlers with Disabilities and Their Families: Participants, Services, and Outcomes. SRI International, California, USA.

16. Jafari Z, Malayeri S, Ashayeri H (2007) The ages of suspicion, diagnosis, amplification, and intervention in deaf children. Int J Pediatr Otorhinolaryngol 71: 35-40.

17. Prendergast SG, Lartz MN, Fiedler BC (2002) Ages of diagnosis, amplification, and early intervention of infants and young children with hearing loss: findings from parent interviews. Am Ann Deaf 147: 24-30.

18. Ha NN, Dung NA, Quang VT (2015) Age for detecting, diagnosing and wearing hearing aids for students in Hai Phong hearing impaired school. Journal of Preventive Medicine 8: 420.

19. Hai TT, Chau CM, Thuy NTM, Lung PQ, Chuong TV (2010) Community-based rehabilitation curriculum Hanoi: Medical publishing house.

20. Hai TT, Tuong TQ, Hoa DTP, Chau CM, Chương TV, et al. (2014) Guidelines for early identification, early intervention for children with disabilities Hanoi: Ministry of Health.

21. Crocker AC, Sules SB, Staub RU, Culliane M, Shishmanian E (1989) The Systems of Health Care Delivery. In: Rubin IL, Crocker AC (Ed.). Developmental Disabilities: Delivery of Medical Care for Children and Adults, Lea \& Febiger, USA, Pg no: 30-47.

22. Mann JR, Crawford S, Wilson L, McDermott S (2008) Does race influence age of diagnosis for children with developmental delay? Disabil Health J 1: $157-162$.

23. WHO (1989) Guide for local supervisors: Training in the community for people with disabilities. WHO, Geneva, Switzerland, Pg no: 1-70.

24. The National Assembly (2010) Law No. 51/2010 / QH12: Law on Persons with Disabilities. Parliament, Hanoi, Vietnam, Pg no: 1-8.

25. Hoa NT, Thuy NTM (2016) Knowledge and factors related to early disability detection among caregivers of children under 3 years old in Nam Thang commune, Tien Hai district, Thai Binh province, in 2015. Journal of Public Health 40: 57-62.
26. Hoa HT (2015) Knowledge, attitude, practice of early detection - early intervention with disabilities in children under 6 years of commune health workers in Bao Thang district, Lao Cai province in 2015 (masters degree in health) The Hanoi School of Public Health, Hanoi, Vietnam.

27. Thuy NTM (2013a) Shortcomings of the rehabilitation service delivery system at public health facilities. Journal of Public Health 29: 17-21.

28. Barlindhaug G, Umar E, Wazakili M, Emaus N (2016) Living with disabled children in Malawi: Challenges and rewards. Afr J Disabil 5: 254.

29. UNICEF, Bộ Lao động, Thương Binh và xã hội (2010) Báo cáo phân tích tình hình trẻ em Việt Nam. UNICEF, Hanoi, Vietnam, Pg no: 1-314.

30. Thuy NTM (2013b) Access to information and rehabilitation services of people with disabilities in some residential areas in the Red River Delta. Military Medical and Pharmaceutical Journal 38: 154-160.

31. Bình TT, Phong VH, Thảo VP, Linh NT, Vản KH, et al. (2017) Xóa bổ kỳ thi: Quan điểm đánh giá của người khuyết tật. Nhà Xuất bản tri thức, $\mathrm{Pg}$ no: $1-184$.

32. WHO \& UNICEF (2012) Early Childhood Development and disability: A discussion paper. World Health Organization, Geneva, Switzerland.

33. Ha VS, Whittaker A, Rodger S (2017) Assessment and Diagnosis of Autism Spectrum Disorder in Hanoi, Vietnam. Journal of Child and Family Studies 26: 1334-1344.

34. Christensen DL, Maenner MJ, Bilder D, Constantino JN, Daniels J, et al. (2019) Prevalence and Characteristics of Autism Spectrum Disorder Among Children Aged 4 Years - Early Autism and Developmental Disabilities Monitoring Network, Seven Sites, United States, 2010, 2012, and 2014. MMWR Surveill Summ 68: 1-19.

35. Ministry of Education and Training (2008a) Decision: No. 02/2008/ QD-BGDDT - Promulgating the Regulation on Non-Preschool Teacher Standards. Ministry of Education and Training, Hanoi, Vietnam.

36. Ministry of Education and Training (2008b) Decision: No. 14/2008 / QD-BGDDT - Promulgating the Charter School Charter. Ministry of Education and Training, Hanoi, Vietnam.

37. The Ministry of Education and Training (2010) Circular No. 23/2010 TT-BGDDT- Promulgating the Regulation on Children's Development Standards Year Old. The Ministry of Education and Training, Hanoi, Vietnam.

38. Ministry of Education and Training (2016) Report on the summary school year 2015-2016 and deployment of tasks in 2016-2017. Hanoi, Vietnam.

39. McKenzie K, Megson P (2012) Screening for intellectual disability in children: a review of the literature. J Appl Res Intellect Disabil 25: 80-87.

40. Thuy NTM (2006) Testing the management model and assessing the impact of maternal education on disability and rehabilitation for children with disabilities under 6 years old in Hoai Duc District, Ha Tay, 20062007. Ministry of Health, Ha Tay, Vietnam.

41. Hoa NT, Thuy NTM (2016) Practice on early detection of disabilities and related factors among caregivers of children under 3 years old in the commune Nam Thang in Tien Hai district located in Thai Binh province in 2015. Journal of Public Health 40: 29-34

42. Theeranate K, Chuengchitraks S (2005) Parent's Evaluation of Developmental Status (PEDS) detects developmental problems compared to Denver II. J Med Assoc Thai 3: 188-192. 


\section{If}

Advances In Industrial Biotechnology | ISSN: 2639-5665

Advances In Microbiology Research | ISSN: 2689-694X

Archives Of Surgery And Surgical Education | ISSN: 2689-3126

Archives Of Urology

Archives Of Zoological Studies | ISSN: 2640-7779

Current Trends Medical And Biological Engineering

International Journal Of Case Reports And Therapeutic Studies | ISSN: 2689-310X

Journal Of Addiction \& Addictive Disorders | ISSN: 2578-7276

Journal Of Agronomy \& Agricultural Science | ISSN: 2689-8292

Journal Of AIDS Clinical Research \& STDs | ISSN: 2572-7370

Journal Of Alcoholism Drug Abuse \& Substance Dependence | ISSN: 2572-9594

Journal Of Allergy Disorders \& Therapy | ISSN: 2470-749X

Journal Of Alternative Complementary \& Integrative Medicine | ISSN: 2470-7562

Journal Of Alzheimers \& Neurodegenerative Diseases | ISSN: 2572-9608

Journal Of Anesthesia \& Clinical Care | ISSN: 2378-8879

Journal Of Angiology \& Vascular Surgery | ISSN: 2572-7397

Journal Of Animal Research \& Veterinary Science | ISSN: 2639-3751

Journal Of Aquaculture \& Fisheries | ISSN: 2576-5523

Journal Of Atmospheric \& Earth Sciences | ISSN: 2689-8780

Journal Of Biotech Research \& Biochemistry

Journal Of Brain \& Neuroscience Research

Journal Of Cancer Biology \& Treatment | ISSN: 2470-7546

Journal Of Cardiology Study \& Research | ISSN: 2640-768X

Journal Of Cell Biology \& Cell Metabolism | ISSN: 2381-1943

Journal Of Clinical Dermatology \& Therapy | ISSN: 2378-8771

Journal Of Clinical Immunology \& Immunotherapy | ISSN: 2378-8844

Journal Of Clinical Studies \& Medical Case Reports | ISSN: 2378-8801

Journal Of Community Medicine \& Public Health Care | ISSN: 2381-1978

Journal Of Cytology \& Tissue Biology | ISSN: 2378-9107

Journal Of Dairy Research \& Technology | ISSN: 2688-9315

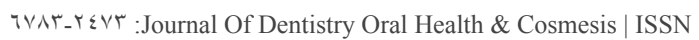

Journal Of Diabetes \& Metabolic Disorders | ISSN: 2381-201X

Journal Of Emergency Medicine Trauma \& Surgical Care | ISSN: 2378-8798

Journal Of Environmental Science Current Research | ISSN: 2643-5020

Journal Of Food Science \& Nutrition | ISSN: 2470-1076

Journal Of Forensic Legal \& Investigative Sciences | ISSN: 2473-733X

Journal Of Gastroenterology \& Hepatology Research | ISSN: 2574-2566
Journal Of Genetics \& Genomic Sciences | ISSN: 2574-2485

Journal Of Gerontology \& Geriatric Medicine | ISSN: 2381-8662

Journal Of Hematology Blood Transfusion \& Disorders | ISSN: 2572-2999

Journal Of Hospice \& Palliative Medical Care

Journal Of Human Endocrinology | ISSN: 2572-9640

Journal Of Infectious \& Non Infectious Diseases | ISSN: 2381-8654

Journal Of Internal Medicine \& Primary Healthcare | ISSN: 2574-2493

Journal Of Light \& Laser Current Trends

Journal Of Medicine Study \& Research | ISSN: 2639-5657

Journal Of Modern Chemical Sciences

Journal of Nanotechnology Nanomedicine \& Nanobiotechnology | ISSN: 2381-2044

Journal Of Neonatology \& Clinical Pediatrics | ISSN: 2378-878X

Journal Of Nephrology \& Renal Therapy | ISSN: 2473-7313

Journal Of Non Invasive Vascular Investigation | ISSN: 2572-7400

Journal Of Nuclear Medicine Radiology \& Radiation Therapy | ISSN: 2572-7419

Journal Of Obesity \& Weight Loss | ISSN: 2473-7372

Journal Of Ophthalmology \& Clinical Research | ISSN: 2378-8887

Journal Of Orthopedic Research \& Physiotherapy | ISSN: 2381-2052

Journal Of Otolaryngology Head \& Neck Surgery | ISSN: 2573-010X

Journal Of Pathology Clinical \& Medical Research

๑ รุ_หษ १: Journal Of Pharmacology Pharmaceutics \& Pharmacovigilance | ISSN

Journal Of Physical Medicine Rehabilitation \& Disabilities | ISSN: 2381-8670

Journal Of Plant Science Current Research | ISSN: 2639-3743

Journal Of Practical \& Professional Nursing | ISSN: 2639-5681

Journal Of Protein Research \& Bioinformatics

Journal Of Psychiatry Depression \& Anxiety | ISSN: 2573-0150

Journal Of Pulmonary Medicine \& Respiratory Research | ISSN: 2573-0177

Journal Of Reproductive Medicine Gynaecology \& Obstetrics | ISSN: 2574-2574

Journal Of Stem Cells Research Development \& Therapy | ISSN: 2381-2060

Journal Of Surgery Current Trends \& Innovations | ISSN: 2578-7284

Journal Of Toxicology Current Research | ISSN: 2639-3735

Journal Of Translational Science And Research

Journal Of Vaccines Research \& Vaccination | ISSN: 2573-0193

Journal Of Virology \& Antivirals

Sports Medicine And Injury Care Journal | ISSN: 2689-8829

Trends In Anatomy \& Physiology | ISSN: 2640-7752

Submit Your Manuscript: https://www.heraldopenaccess.us/submit-manuscript 